\title{
INTERIM LETTER REPORT VERIFICATION SURVEY OF 19 GRIDS IN THE LESTER FLAT AREA, DAVID WITHERSPOON, INC. 1630 SITE KNOXVILLE, TENNESSEE
}

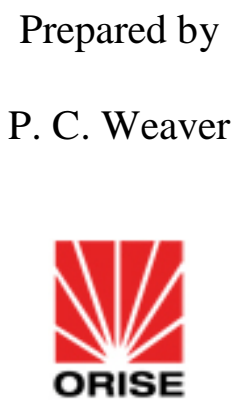

DOE CONTRACT NO. DE-AC05-06OR23100

Prepared for the

U.S. Department of Energy

\section{INTERIM LETTER REPORT}

OCTOBER 2008

Approved for public release; further dissemination unlimited. 


\section{INTERIM LETTER REPORT VERIFICATION SURVEY OF 19 GRIDS AT THE DAVID WITHERSPOON, INC. 1630 SITE KNOXVILLE, TENNESSEE}

\section{INTRODUCTION}

The David Witherspoon Inc. (DWI) Site, located at 1630 Maryville Pike in Knoxville, Tennessee, received, processed, stored, and shipped scrap metal that was contaminated with radiological and chemical substances. The DWI site received a variety of wastes for disposal from U.S. Department of Energy (DOE) Oak Ridge Operation sites as early as the 1970's. Past monitoring at the site indicated that improper handling of the waste had resulted in the contamination at 1630 DWI. Characterization surveys and analyses identified numerous radiological and chemical contaminants, including uranium, thorium, heavy metals, polychlorinated biphenyls (PCBs), asbestos, and organic compounds. The contaminants have been noted in various media on the site, including debris, soil, sediment, groundwater, and surface water. There were no buildings located in the subject areas during site operations. The DOE's decommissioning contractor, Bechtel Jacobs Company, LLC. (BJC), has performed characterization surveys, subsequent remediation, and final status surveys within the subject area. The areas are awaiting backfilling pending results from the Independent Verification (IV) survey.

The DOE requested that the Oak Ridge Institute for Science and Education (ORISE) perform a verification survey of 19 available grids located in the Lester Flat Area at the DWI. The survey grids included E11, E12, E13, F11, F12, F13, F14, F15, G15, G16, G17, H16, H17, H18, X16, X17, X18, K16, and J16. During the period of September 8 through 11, 2008, an independent verification team (IVT) from ORISE conducted verification activities that included soil surface scans and sampling in this area (Figure 1).

\section{PROCEDURES}

Site verification activities were performed in accordance with a Project-Specific Plan (PSP) submitted to and approved by DOE (ORISE 2007) and the ORISE Survey Procedures and the ORAU Quality Program Manuals (ORISE 2008a and ORAU 2007). Grid boundaries for the specified survey areas were obtained from maps or coordinates provided by the contractor. This information aided ORISE in developing a georeferenced map using ArcGIS software that was uploaded to global positioning systems (GPS). Therefore, field data can be electronically captured and stored, and positionally located for future reporting. Surface scans were performed using 2 inch by 2 inch sodium iodide (NaI) scintillation detectors coupled to ratemeters with audible output which were also coupled to the GPS systems. The use of the GPS enabled real-time gamma count rate and position data capture. ORISE performed medium to high density gamma scans over approximately $75 \%$ or more of accessible surfaces in the subject grids (Figure 2).

Prior to survey activities, a reference map was uploaded into Visual Sampling Plan (VSP) version 5 software (PNL 2007). The VSP software was used to determine the number of samples required to provide an adequate statistical representation of the area based on the assumed mean concentration and variability of the primary contaminant of concern, uranium-238 (U-238) and to generate the random soil sampling locations. Twenty-three surface soil samples ( 0 to $0.15 \mathrm{~m})$ for radiological analyses were generated of which 21 locations were sampled (see Findings and Results section for 
explanation). The coordinates for the random soil sample locations were uploaded into a hand-held GPS unit (Figure 3). Static gamma radiation measurements were recorded prior to and following the collection of each radiological soil sample.

\section{SAMPLE ANALYSIS AND DATA INTERPRETATION}

The soil samples were returned to the ORISE laboratory in Oak Ridge, TN for analysis and interpretation. Sample analyses were performed in accordance with the ORISE Laboratory Procedures Manual (ORISE 2008b). Soil samples were analyzed by gamma spectroscopy and spectra were reviewed for U-238, Ra-226, Th-232, and other gamma-emitting radionuclides. The results were reported in units of picocuries per gram $(\mathrm{pCi} / \mathrm{g})$.

\section{FINDINGS AND RESULTS}

Two of the random sample locations (locations 036 and 042) were in grids that were inaccessible as a result of the vegetation or within the capped landfill Grids E11 and E13 (both partial grids). Also, three sampling locations (within Grids F15 and H16) were outside of the boundary of the remediated portion of the grids; however, these samples were relocated to within a meter of the original pre-generated random location inside the grid's remediation boundary. As a result of this action, these samples are no longer considered random but now judgmental. Therefore, 18 random soil samples and three judgmental soil samples were collected.

The ambient background radiation level typically ranged from 6,100 to 6,600 counts per minute (cpm). Radiation levels on contact with the soil surface ranged from 8,300 to 14,100 cpm, including background. The a priori scan MDC is approximately $115 \mathrm{pCi} / \mathrm{g}$ for U-238 (estimated from Table 6.4 of NUREG-1507).

The gamma spectroscopy results for samples S037 to S041 and S043 to S058 are provided in Table 1. The predominant radionuclide at the site is U-238. The U-238 concentrations in soil samples collected by ORISE ranged from 0.77 to $8.49 \mathrm{pCi} / \mathrm{g}$. The mean U-238 concentration for the Lester Flat surveyed grids was $1.86 \mathrm{pCi} / \mathrm{g}$. The highest U-238 concentration $(8.49 \mathrm{pCi} / \mathrm{g})$ was sample S056 collected in Grid G17. Ra-226 concentrations ranged from 0.60 to $1.11 \mathrm{pCi} / \mathrm{g}$ and Th-232 concentrations ranged from 0.90 to $1.71 \mathrm{pCi} / \mathrm{g}$. The spectra were also reviewed for other identifiable radionuclide photopeaks which have been included in Table 1. All sample data were compared to the $500 \mathrm{pCi} / \mathrm{g}$ "hot-spot" criterion for U-238, as specified in the PSP (ORISE 2007). The results for both random and judgmental ORISE samples were less than the "hot-spot" criterion.

\section{CONCLUSIONS}

It is ORISE's position that the concentration of the radionuclides of concern for the 19 subject grids meets the release limits established for the DW1 1630 site and verify the BJC final status survey results. 


\section{FIGURES}




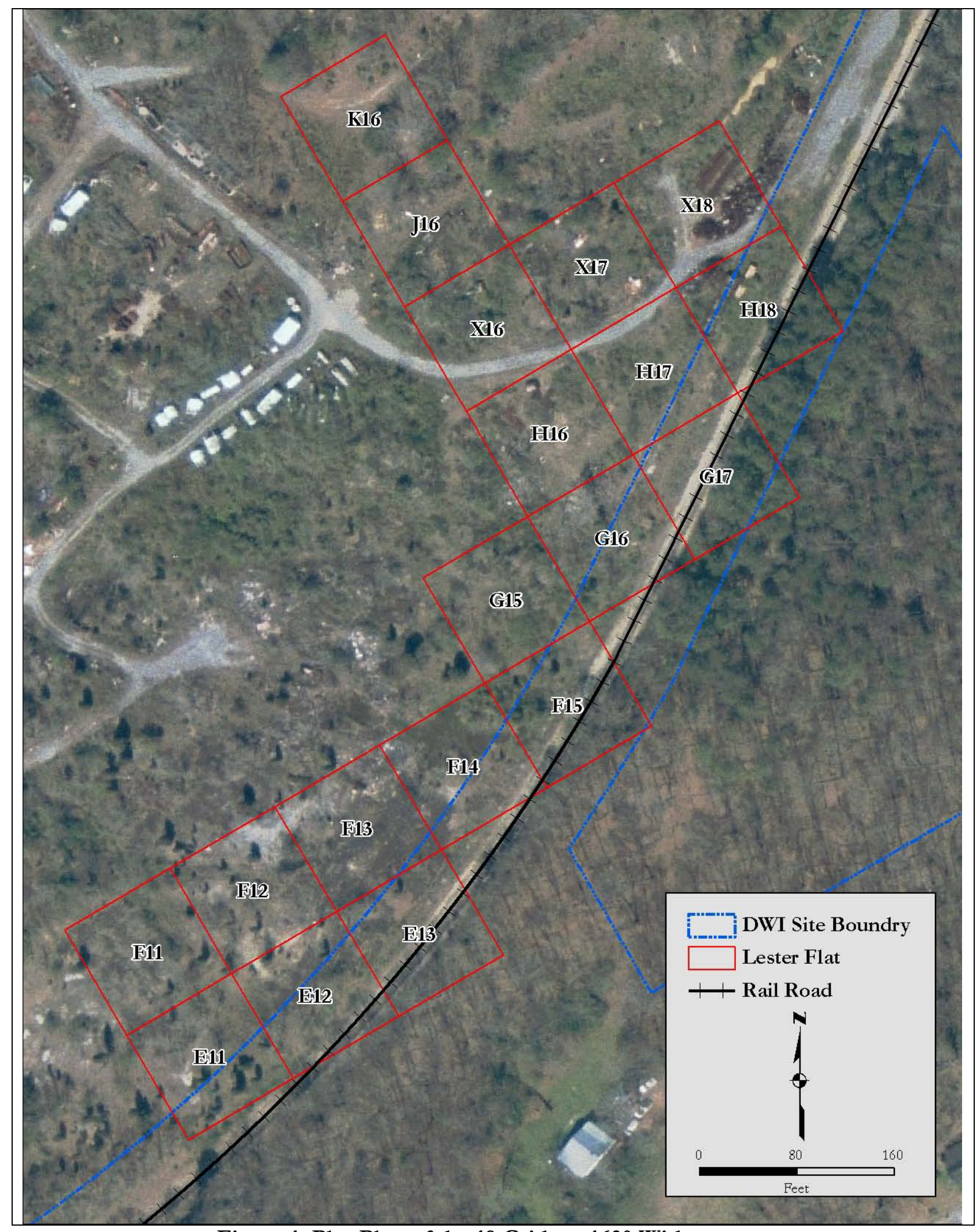

Figure 1: Plot Plan of the 19 Grids at 1630 Witherspoon 


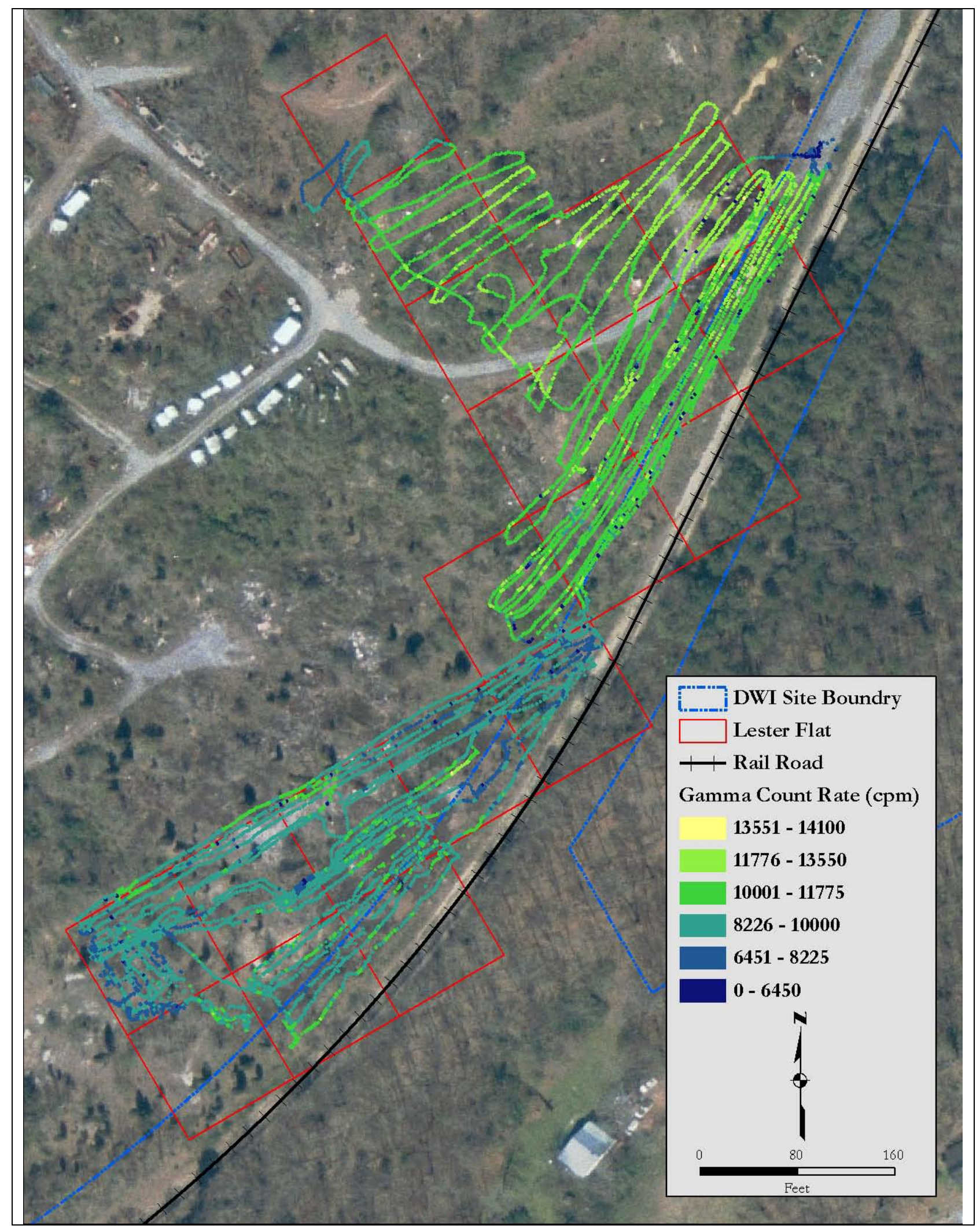

Figure 2: Gamma Walkover Scans of 19 Grids at 1630 Witherspoon 


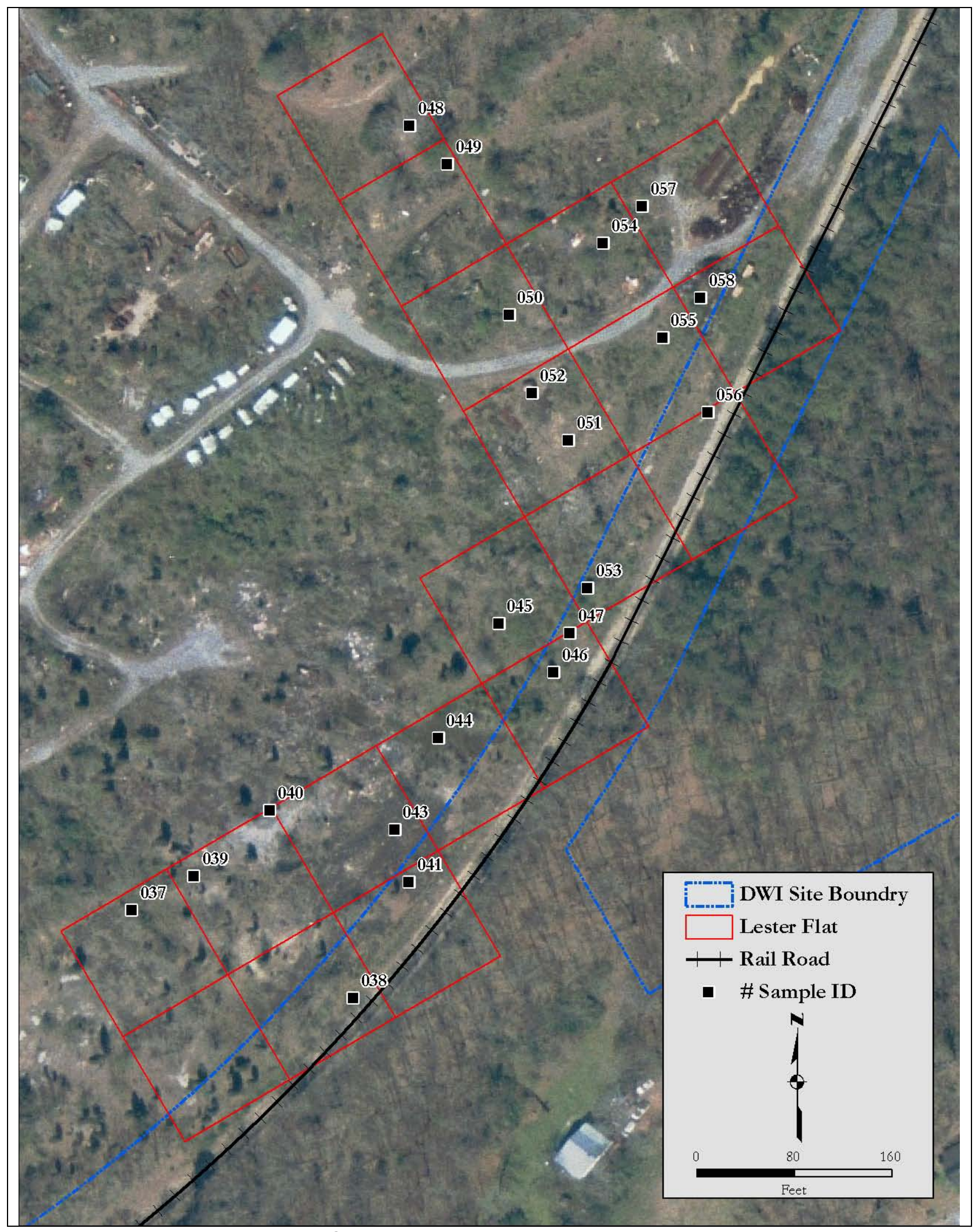

Figure 3: Sampling Locations at 1630 Witherspoon 
TABLES 
TABLE 1

\section{RADIONUCLIDE CONCENTRATIONS IN SOIL \\ 19 GRIDS LOCATED IN THE LESTER FLAT AREA \\ DAVID WITHERSPOON, INC. 1630 SITE \\ KNOXVILLE, TENNESSEE}

\begin{tabular}{|c|c|c|c|c|c|c|c|c|}
\hline \multirow{2}{*}{$\begin{array}{c}\text { Sample } \\
\text { ID/Location }\end{array}$} & \multicolumn{8}{|c|}{ Radionuclide Concentration in Soil Samples (pCi/g) } \\
\hline & Cs-137 & Ra-226 & Th-228 & Th-232 & Total $\mathrm{Th}^{\mathrm{b}}$ & $\mathrm{U}-238$ & U-235 & Total $\mathbf{U}^{\mathrm{c}}$ \\
\hline S037 & $0.03 \pm 0.04^{\mathrm{d}}$ & $0.71 \pm 0.07$ & $1.14 \pm 0.10$ & $1.21 \pm 0.17$ & $2.35 \pm 0.20$ & $1.39 \pm 0.33$ & $0.15 \pm 0.08$ & $2.93 \pm 0.66$ \\
\hline S038 & $-0.01 \pm 0.06$ & $0.67 \pm 0.08$ & $1.28 \pm 0.11$ & $1.57 \pm 0.24$ & $2.85 \pm 0.26$ & $1.18 \pm 0.46$ & $0.03 \pm 0.29$ & $2.39 \pm 0.96$ \\
\hline S039 & $0.03 \pm 0.03$ & $0.60 \pm 0.05$ & $0.82 \pm 0.07$ & $0.94 \pm 0.13$ & $1.76 \pm 0.15$ & $1.13 \pm 0.24$ & $0.12 \pm 0.06$ & $2.38 \pm 0.48$ \\
\hline S040 & $0.00^{\mathrm{e}} \pm 0.03$ & $0.74 \pm 0.08$ & $1.37 \pm 0.11$ & $1.28 \pm 0.19$ & $2.65 \pm 0.22$ & $1.17 \pm 0.74$ & $0.13 \pm 0.08$ & $2.5 \pm 1.5$ \\
\hline S041 & $0.02 \pm 0.01$ & $0.78 \pm 0.07$ & $0.95 \pm 0.08$ & $0.90 \pm 0.14$ & $1.85 \pm 0.16$ & $0.77 \pm 0.25$ & $0.10 \pm 0.45$ & $1.64 \pm 0.67$ \\
\hline S043 & $0.01 \pm 0.01$ & $1.11 \pm 0.10$ & $0.87 \pm 0.08$ & $0.92 \pm 0.14$ & $1.79 \pm 0.16$ & $1.36 \pm 0.31$ & $0.09 \pm 0.09$ & $2.81 \pm 0.63$ \\
\hline S044 & $0.04 \pm 0.04$ & $0.77 \pm 0.08$ & $1.03 \pm 0.10$ & $1.17 \pm 0.19$ & $2.20 \pm 0.21$ & $1.08 \pm 0.42$ & $0.00 \pm 0.12$ & $2.16 \pm 0.85$ \\
\hline S045 & $-0.01 \pm 0.03$ & $0.61 \pm 0.05$ & $1.15 \pm 0.09$ & $1.27 \pm 0.17$ & $2.42 \pm 0.19$ & $0.97 \pm 0.26$ & $0.07 \pm 0.06$ & $2.01 \pm 0.52$ \\
\hline S046 & $0.01 \pm 0.01$ & $0.72 \pm 0.07$ & $1.12 \pm 0.10$ & $1.04 \pm 0.16$ & $2.16 \pm 0.19$ & $1.39 \pm 0.37$ & $0.15 \pm 0.07$ & $2.93 \pm 0.74$ \\
\hline S047 & $0.01 \pm 0.01$ & $0.72 \pm 0.08$ & $1.24 \pm 0.11$ & $1.37 \pm 0.20$ & $2.61 \pm 0.23$ & $1.60 \pm 0.41$ & $0.19 \pm 0.10$ & $3.39 \pm 0.83$ \\
\hline S048 & $0.00 \pm 0.04$ & $0.63 \pm 0.06$ & $1.59 \pm 0.13$ & $1.37 \pm 0.19$ & $2.96 \pm 0.23$ & $1.22 \pm 0.32$ & $0.12 \pm 0.01$ & $2.56 \pm 0.64$ \\
\hline S049 & $0.03 \pm 0.04$ & $0.69 \pm 0.06$ & $1.43 \pm 0.11$ & $1.39 \pm 0.19$ & $2.82 \pm 0.22$ & $1.17 \pm 0.32$ & $0.08 \pm 0.06$ & $2.42 \pm 0.64$ \\
\hline S050 & $0.05 \pm 0.02$ & $0.83 \pm 0.08$ & $1.55 \pm 0.13$ & $1.33 \pm 0.21$ & $2.88 \pm 0.25$ & $0.93 \pm 0.39$ & $-0.06 \pm 0.17$ & $1.80 \pm 0.80$ \\
\hline S051 & $0.03 \pm 0.02$ & $0.86 \pm 0.09$ & $1.39 \pm 0.12$ & $1.15 \pm 0.19$ & $2.54 \pm 0.22$ & $2.19 \pm 0.48$ & $0.17 \pm 0.08$ & $4.55 \pm 0.96$ \\
\hline
\end{tabular}


TABLE 1 (Continued)

\section{RADIONUCLIDE CONCENTRATIONS IN SOIL 19 GRIDS LOCATED IN THE LESTER FLAT AREA \\ DAVID WITHERSPOON, INC. 1630 SITE \\ KNOXVILLE, TENNESSEE}

\begin{tabular}{|c|c|c|c|c|c|c|c|c|}
\hline \multirow{2}{*}{$\begin{array}{c}\text { Sample } \\
\text { ID/Location }\end{array}$} & \multicolumn{8}{|c|}{ Radionuclide Concentration in Soil Samples (pCi/g) } \\
\cline { 2 - 9 } & Cs-137 & Ra-226 & Th-228 & Th-232 & Total Th $^{\mathbf{b}}$ & U-238 & U-235 $^{\text {Total U }^{\mathrm{c}}}$ \\
\hline \hline S052 & $0.01 \pm 0.04$ & $0.79 \pm 0.08$ & $1.40 \pm 0.12$ & $1.71 \pm 0.24$ & $3.11 \pm 0.27$ & $1.92 \pm 0.46$ & $-0.14 \pm 0.29$ & $3.70 \pm 0.96$ \\
\hline S053 & $-0.04 \pm 0.05$ & $0.72 \pm 0.08$ & $1.49 \pm 0.12$ & $1.51 \pm 0.22$ & $3.00 \pm 0.25$ & $1.62 \pm 0.38$ & $0.14 \pm 0.02$ & $3.38 \pm 0.76$ \\
\hline S054 & $-0.02 \pm 0.04$ & $0.76 \pm 0.07$ & $1.57 \pm 0.13$ & $1.49 \pm 0.21$ & $3.06 \pm 0.25$ & $1.64 \pm 0.38$ & $0.04 \pm 0.16$ & $3.32 \pm 0.78$ \\
\hline S055 & $0.01 \pm 0.04$ & $0.86 \pm 0.08$ & $1.28 \pm 0.11$ & $1.27 \pm 0.19$ & $2.55 \pm 0.22$ & $3.47 \pm 0.49$ & $0.15 \pm 0.08$ & $7.09 \pm 0.98$ \\
\hline S056 & $0.07 \pm 0.02$ & $0.77 \pm 0.08$ & $0.88 \pm 0.08$ & $1.05 \pm 0.17$ & $1.93 \pm 0.19$ & $8.49 \pm 0.82$ & $0.53 \pm 0.11$ & $17.5 \pm 1.6$ \\
\hline S057 & $0.02 \pm 0.04$ & $0.60 \pm 0.06$ & $1.48 \pm 0.12$ & $1.40 \pm 0.19$ & $2.88 \pm 0.22$ & $2.30 \pm 0.36$ & $0.13 \pm 0.07$ & $4.73 \pm 0.72$ \\
\hline S058 & $-0.02 \pm 0.04$ & $0.62 \pm 0.07$ & $1.43 \pm 0.11$ & $1.35 \pm 0.19$ & $2.78 \pm 0.22$ & $2.00 \pm 0.38$ & $0.04 \pm 0.16$ & $4.04 \pm 0.78$ \\
\hline
\end{tabular}

${ }^{a}$ Refer to Figures 2 and 3 .

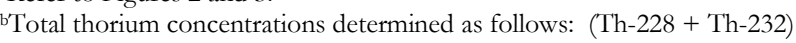

cTotal uranium concentrations determined as follows: (U-238 x 2) + U-235.

Uncertainties represent the $95 \%$ confidence level based on total propagated uncertainties.

Zero values are due to rounding. 


\section{REFERENCES}

Bechtel Jacobs Company LLC. (BJC). Sampling and Analysis Plan for Final Verification of the David Witherspoon, Inc. 1630 Site. Oak Ridge, Tennessee; December 2006.

Bechtel Jacobs Company LLC. Independent Verification Survey at the David Witherspoon Inc. 1630 Site. Oak Ridge, Tennessee; September 8, 2008.

Oak Ridge Associated Universities (ORAU). Quality Program Manual for the Independent Environmental Assessment and Verification Program. Oak Ridge, Tennessee; November 1, 2007.

Oak Ridge Institute for Science and Education (ORISE). Final Project-Specific Plan for Conducting In-Process Reviews and Independent Verification Surveys of Remedial Action Activities at the David Witherspoon, Inc. 1630 Site, Knoxville, Tennessee. Oak Ridge, Tennessee; May 17, 2007.

Oak Ridge Institute for Science and Education. Survey Procedures Manual for the Independent Environmental Assessment and Verification Program. Oak Ridge, Tennessee; January 18, 2008 a.

Oak Ridge Institute for Science and Education. Laboratory Procedures Manual for the Independent Environmental Assessment and Verification Program. Oak Ridge, Tennessee; September 10, 2008b.

Pacific Northwest Laboratory (PNL). Visual Sample Plan Version 5.0 User's Guide. Richland, Washington; September 2007. 